\section{Chapter}

[6]

\title{
Biodiversity conservation to mitigate the impact of climate change on agro-ecosystems
}

\author{
Ananya Mishra1, ${ }^{1,}$, Rohitashw Kumar ${ }^{2}$ and Rishi Richa ${ }^{3}$ \\ ${ }^{1}$ Division of Soil \& Water Engineering, COAE\&T, SKUAST-K, Srinagar, Jammu and Kashmir, India \\ ${ }^{2}$ Division of Irrigation and Drainage Engineering, COAE\&T, SKUAST-K, Srinagar, Jammu and Kashmir, India \\ ${ }^{3}$ Division of Renewable Energy Engineering, COAE\&T, SKUAST-K, Srinagar, Jammu and Kashmir, India
}

\begin{abstract}
Biodiversity, or the diversity of living organisms on Earth, is an important indicator of the planet's health. Climate change mitigation requires preserving biodiversity levels and functional ecosystems; nevertheless, climate change is predicted to create major disturbances to the Earth's natural ecosystems, resulting in loss of biodiversity and a significant decrease in products and services offered to humanity. The present chapter deals with the impact of climate change that is severe to environmental issue that would jeopardize efforts to achieve long-term development and mitigation measures to reduce its impact on biodiversity changes. Furthermore, the impact of local and global species climate change has produced phenological changes in pollinators of flowering plants and insects, resulting in population mismatches, leading to plant and pollinator extinctions, with consequences for the structure of plant-pollinator networks. The loss of biodiversity and rising temperature can have an immediate impact on the water supply, food safety, soil nutrients, and human health. Conservation measure needs to be adopted, the land use pattern can be determined by remote sensing which is particularly valuable for detecting change due to the systematic coverage and lengthy time-series offered by satellite data.
\end{abstract}




\section{Introduction}

The diversity of life on Earth at various levels, from genome to ecosystems, as well as the ecological, evolutionary, and social processes that keep life continuing, is referred to as biodiversity. Climate change forces a worldwide redistribution of life on Earth, whereas species geographical borders are dynamic and time-limited. For coastal, aquatic, and terrestrial species alike, the initial response to climate change is generally a shift in the site to retain favored circumstances. Climate change is expected to be one of the leading causes of global biodiversity loss in the future (Pawson et al., 2013). Various Ecosystems in biodiversity are especially sensitive to climate change, as compared to other life forms, they last for a long time and have a limited ability to react to sudden changes in the environment (Lindner et al. 2010). To understand how climate change impacts biodiversity, one must first comprehend the idea of biodiversity. Biodiversity refers to the overall diversity of all living entities on Earth, including genetic variety, species diversity, and the diversification of ecosystems (forests, coral reefs, and estuary) that they contribute to build and control. Biodiversity includes not only rare, vulnerable, or endangered species, as well as all living creatures, including bacteria, fungus, and invertebrates. Human intervention and activities in natural environments are affecting the biosphere all around the world. Human activities such as expanding agricultural production, urbanization, and resource usage and waste are all having significant impacts on the globe. This impact has led to certain consequences, like pollution, addressed effectively at local or national levels, while others such as ozone layer depletion, have been efficiently addressed through global cooperation. However, many of the effects caused by humans on the biosphere have yet to be completely addressed, and some of these have global implications at an unprecedented scale. As a result, biodiversity change encompasses more than just a decrease in species richness, such as the extinction of long-lived foundation species and their replacement by small, weedy organisms. Henceforth, Hillebrand et al. (2017) have described that biodiversity not only encompasses richness, or the number of species, but also qualities of identity, dominance, and rarities. Changes in climate patterns have had a significant negative influence on various ecosystems. The loss of biodiversity, the extinction of millions of species is a very real result of excessive utilization of natural resources. Climate change, caused by greenhouse gas emissions, can affect the composition of the atmosphere and the living conditions on the Earth's surface for humans and all other species (Thomas and Warner, 2019). Human modification of Earth's ecosystems has affected biodiversity in many parts of the world, including marine, terrestrial, and freshwater ecosystems, and more changes are anticipated as a result of rapid global change (Hillebrand, 2017). Such reductions in biodiversity have resulted in what is usually referred to as a "biodiversity crisis," with cautions that present rates of extinction are unusually high (Pimm et al., 2014).

Biodiversity is the life foundation system of the world where people depend on air, water, and food. The medications produced from wild species save countless lives and alleviate pain for an example of Aspirin, taxol, quinine, and Penicillin. Furthermore, wetlands screen out water toxins, while vegetation absorbs carbon, contributing to the reduction of global warming. Organic stuff, which fertilizes the soil, decays bacteria and fungus. The abundance of natural species and the human standard of living are 
associated with environmental wellness. The link between diversity and long-term viability appears to be becoming stronger. As a consequence, biodiversity conservation is required because humans and other living creatures rely on it. This chapter examines the influence of climate change on biodiversity, as well as its components and mitigation strategies, to understand the loss of diversity.

\section{Types of biodiversity}

The biological resources (genes, species, creatures, ecosystems) and ecological processes are a part and our examples of biodiversity. As a result, biodiversity is examined on three levels:

- Genetic diversity

- Species diversity

- Ecosystem diversity

Genetic diversity: The study of genetic diversity is used to define individuals or societies in comparison to others. It determines the degree of genetic variation in a population, which is a major source of biodiversity. Genes are the basic building blocks of biodiversity, serving as the building resources for the growth of plants, animals, communities, and ecosystems, which are a source of the huge variety that we are seeking to maintain, enjoy and utilize. Genetic variety in shape distinguishes individuals, populations, subspecies, species, and eventually kingdoms of life on Earth. Individual genetic diversity shows the presence of several alleles in the gene, resulting in a wide range of genotypes among species (Mukhopadhyay and Bhattacharjee, 2016). Genetic diversity is essential for survival and adaptation, as it allows for the continuation and advancement of adaptive processes that are essential for evolutionary success and, to some extent, human existence. Time, space, and fitness can all be used to measure survival and adaptation. Adaptation, genetic stability, and variability are all fitness factors. Extinction can occur as a result of biotic or abiotic pressures, such as competition, predation, parasitism, and disease, or isolation and habitat alteration as a consequence of natural calamities, slow geological and climatic change, or human activity (Rao and Hodgkin, 2002).

Species diversity: Species diversity, of living organisms, is one of the three layers of biological diversity, along with genetic diversity within species, species diversity, and ecological or community diversity. Biodiversity is however confounded with species diversity in many environmental assessments and the number of species in a given area is assessed (species richness). While the species is frequently thought of as the most fundamental unit in ecology, measuring the number of species to evaluate diversity raises several difficulties (Kempton, 2002). Trees offer basic needs and habitat for other species, specie variety, and stand structure are critical for forest biodiversity (Reilly and Spies, 2015). Furthermore, an understanding of forest diversity and stand structure is crucial for climate change control since manipulating them can result in the formation of forests that result in less emission (Sevegnani, 2016; Jenkins et al., 2017).

Ecosystem diversity: On Earth, there are many separate ecosystems, each with its complement of 
diverse interconnected species based on habitat characteristics. Biodiversity is however confounded with species diversity in many environmental assessments and the number of species in a given area is assessed are examples of distinct ecosystems. Farmland and grazing pastures are examples of man-made environments in each region. The words 'eco' and 'system' refer to an area of the planet and to coordinating bodies. Live creatures of a habitat and their surroundings work as a single entity together. An ecosystem is a sort of an ecological unit which engage a natural interaction of life forms and the environment. The biotic community, which includes plants, animals, and other living organisms, is referred to as life. The biotope spanning the physical region of life is referred to as the environment (Balasubramanian, 2017).

\section{Climate change and biodiversity}

The term "climate" refers to the average weather conditions at a given location on the planet. Climate is usually described in terms of projected temperature, rainfall, and wind conditions based on past data. A change in the average climate or climate variability that lasts for a long time is referred to as "climate change". The climate of the Earth has always fluctuated due to changes in the Earth's orbit, the sun's energy output, volcanic activity, the geographic distribution of the Earth's landmasses, and other internal and external events. This form of long-term climate change is referred to as "natural climate change" by scientists. The Earth has endured frequent cold periods in the past as a result of natural climate change when glaciers covered vast portions of the Earth's surface. Warmer times on Earth have also occurred, with sea levels far higher than usual levels. According to the United Nations Framework Convention On Climate Change (UNFCCC, 2007), climate change will have profound impacts on the ecosystem, as well as the socioeconomic and related sectors of water resources, agricultural production, public health, terrestrial ecosystems, and biodiversity, and coastal zones. The fundamental cause of global warming is the rise in temperature caused by the entrapment of greenhouse gases. Carbon dioxide, methane, nitrous oxides, and chlorine and bromine-containing chemicals are among them. The accumulation of these gases in the atmosphere alters the atmosphere's radiative equilibrium. Greenhouse gases absorb some of the Earth's outgoing radiation and re-radiate it back towards the surface, which causes an overall impact to warm the Earth's surface and the lower atmosphere. Changes in rainfall patterns are predicted to cause drought conditions and flooding. Glacier melt can result in flooding and soil erosion. Rising temperatures may force agricultural growth seasons to alter, posing a threat to food security.

\section{Impacts of climate change on biodiversity}

Global data increase over the last two decades has indicated that the last half century's climate change has been a leading driver in creating considerable changes in biodiversity in numerous locations and habitat types (Shen and Ma, 2014). Climate change directly impacts biodiversity by changing basic 
habitat elements such as temperature and rainfall, and it triggers climatic risks such as drought, flooding, cooling, thunder, and temperature rise. These changes act as natural drivers of biodiversity dynamics, potentially amplifying secondary effects. Climate change has the potential to lower population biological variation as a result of directional selection and accelerated migration, which could have an influence on ecological processes and resilience (Bellard et al., 2012). Climate change has produced phenological changes in angiosperms and insect carriers, resulting in population mismatches, leading in plant and pollinator extinctions, with ramifications for the structure and composition networks (Kiers et al., 2010). Climate change may produce significant changes in native plants, putting biome integrity at risk at higher biodiversity levels. The multiple components of climate change are projected to be the major causes of biodiversity loss at all levels, alongside anthropogenic stressors. The loss of biodiversity as a result of climate change has altered the pattern and dynamics of energy and material circulation, either directly or indirectly (Zong and Wang, 2017). This has also resulted in the adaptation of the conversion of biological resources into useful commodities and services, specifically, the transformation of pastures and forests to croplands (Lambin and Meyfroidt, 2011). The generation of biological source of food, power and textiles and forests transformation for agriculture can have a direct effect on greenhouse gas emissions (Burnham and Ma, 2015). According to Thuiller (2007), each $10^{\circ} \mathrm{C}$ increase in temperature shifts the zone of occurrence of several specialist species by 160 meters vertically and 160 kilometres horizontally. Although the precise impact of climate change on India's natural resources has yet to be determined at scientific level. It has been revealed that greenhouse gas emissions are endangering biodiversity all across the world. Intergovernmental Panel on Climatic Change IPCC (2007) predicted in 2007 that by the end of the twenty-first century, global surface temperatures might rise by 1.8 to 40 degrees Celsius, and found that an increase of 1.5 to 2.50 degrees Celsius would risk the extinction of 20 to 30 percent of the world's plant and animal species. The climate has a significant impact on people's lives and livelihoods in socio-economic development. The climate has warmed by 0.890 degrees Celsius (0.69 to 1.080 degrees Celsius) between 1901 and 2012, owing primarily to anthropogenic activity (IPCC, 2013). Climate change and extreme weather events like hurricanes will have an impact on coastal development, water supply, energy, agriculture, and health. Walther (2010) described climate change as a cause of abiotic environments to shift, affecting biological systems and processes. The rate, amount, and nature of climate change, as well as ecological sensitivity and adaptation capability to environmental change, all influence biological responses. It's also been noted that a combination of these elements has an impact on biodiversity at all levels. Figure 1 shows the detailed impact of climate change on various components of biodiversity.

\section{Impacts on species}

Biodiversity planning is difficult in a changing environment since species population, might be declined or even vanish at some locations, flourish in others, and extend into new regions beyond their current ranges (Bellard et al., 2012). Over the past 200 years, world rates of extinction have rapidly climbed to considerably higher than in the last few years (Ceballos et al., 2015). Global concern has been expressed about these changes that may harm protected area networks, which are one of the most 


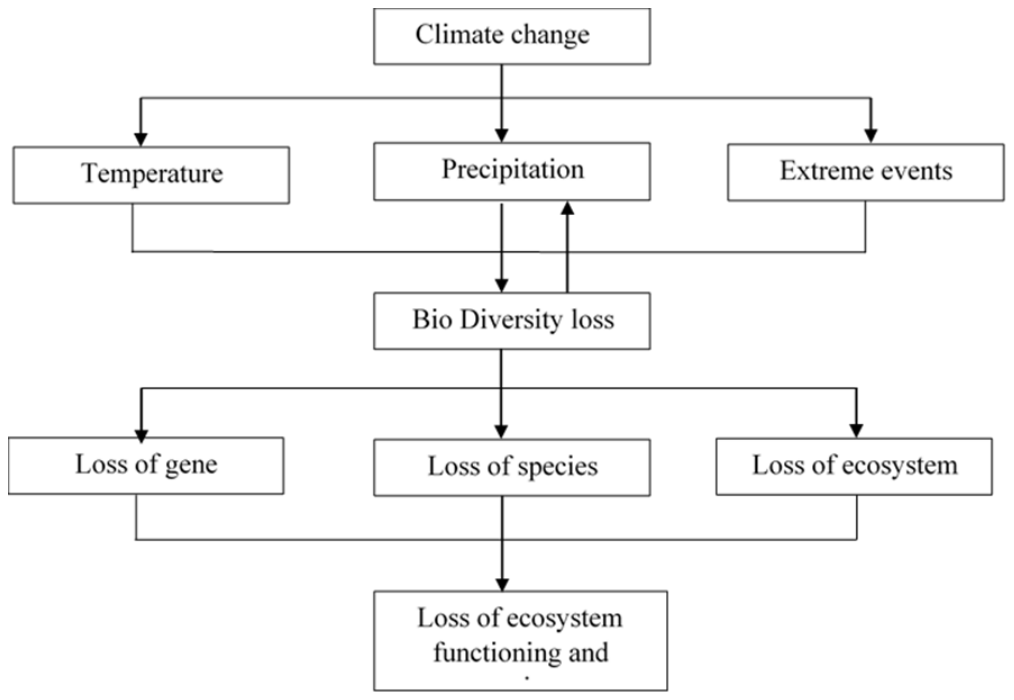

Figure 1. Link between climate change and its impacts on biodiversity and ecosystem services, and the impact of biodiversity loss on climate change (Sintayehu, 2018).

important instruments for reducing biodiversity loss. There are also projected climate change to have an influence on terrestrial biodiversity, including declines in the range and abundance of species (Warren et al., 2013). Protected areas, on the other end, must conserve populations large enough to have a low risk of extinction at the species level (McCarthy et al., 2011). While climate plays a key role in organizing large-scale diversity, the association between species-specific responses to patterns is well understood. Many ecological studies at macro scale have concentrated on pattern in local site diversity (alpha diversity), which is generally quantified in terms of species richness. For example, it is well known that species richness declines with increasing latitude and grows as the temperature rises (Davey et al., 2013). Beyond alpha diversity, species composition discrepancies between sites (beta diversity) and regional species pool diversity (gamma diversity) also play essential roles in regulating community richness and composition at different scales. These scales depend on the prediction of net changes in diversity. An increase in local richness may not lead to regional gains. Ward and Masters (2006) studied that $40 \%$ of the main insect pest species in North America are introduced species although comprises only $2 \%$ of total biodiversity of the insects. Likewise, roughly $30 \%$ of all insect and mite pests are introduced in Britain, while more notably, 62\% are non-native of 29 major insect forest pests. Johnston et al. (2013) conducted a study to focus on two key bird assemblages of international importance; seabird breeding and wintering waters. The apparent strength of the network of protected areas does not ensure that every species is safeguarded from climate change repercussions. According to studies, by $2080,41 \%$ of breeding seabirds and $53 \%$ of wintering waterbirds in the UK may suffer population declines of more than $25 \%$ due to climate change. Negative consequences in protected area 
populations, however, may be less negative than influences in the surrounding landscape. The impact of climate change on the population size of the species assembly across the national protected areas network, hence continuing the protection of huge numbers of breeding seabirds and wintering water-birds existing in the UK would be feasible over the next 70 years. Although certain species and assemblages are not protected from an inherent consequences of climate change and the assembly structure at each site may vary, these sites will continue to be locations where some fragile populations are conserved. Species with many characteristics could be classified as susceptible to climate change and risk in the future. From the 252 essential protected vertebrate species at the county level in China, the percentage lost (PSL) was $27.2 \%$ during about 50 years. Average mammalian PSL (47.74\%) was higher than the amphibian and reptile ones and higher than the birds (28.8\%) (He et al., 2018). The biodiversity of the species, their genes, and habitats include diversity, abundance, and identity (IPBES, 2019). In green environments, the function of genuine biodiversity is still very understood. Biodiversity covers the diversity i.e. (animal species, plants, fungus, and microbes) of species, but it also includes genes and diverse ecosystems within those species. Biodiversity declines, however, threaten the quality of life of all people, wealthy and poor, at an unprecedented rate. Environments provide supplies of food, fuel, fresh water, medicines, and other material, regulating the local and global climate, air quality, pollination processes, pests, and vector-borne diseases, provide habitat for biological diversity, and preserve genetic variation.

\section{Impacts on human health}

According to World Health Organization (WHO, 2015) definition Health "is a complete condition of physical and mental well-being, not only the absence of sickness or illness." Health status has substantial social, economic, behavioural, environmental. However, a wider view of health, includes other species, ecosystems, and fundamental unit of the ecological foundations. In reaction to irresponsible biodiversity management, the COVID-19 pandemic exposes public health risks around the globe (IPBES, 2020). In the formation of global and regional policy development, the importance of the underlying connections between biodiversity and the health of human is more and more recognized (Khaine et al., 2017). Global temperature rises and ozone layer depletion as a result of climate change have resulted in pain and skin disorders, which have a long-term influence on human health. Climate change has an immediate influence on human health, economy, water supply, and food security (Michelle et al., 2012; Adelodun et al., 2021a, b). At multiple geographic and temporal levels, the relationships between biodiversity and health are evident. On a global scale, ecosystems and biodiversity play a critical role in establishing the state of the Earth System, controlling material and energy fluxes, and responding to sudden and gradual changes. The human microbiota, symbiotic microbial communities present in our intestines, skin, breathing systems, can contribute to our nutrition, assist control our immune system, and avoid illnesses. Land-use change, habitat loss, pollution, invasive species, and climate change are direct drivers of biodiversity loss. Many of these drivers directly affect human health and its biodiversity implications. The continuing decline in biodiversity, including ecosystem loss or degradation, reduces the capacity of biodiversity and ecosys- 


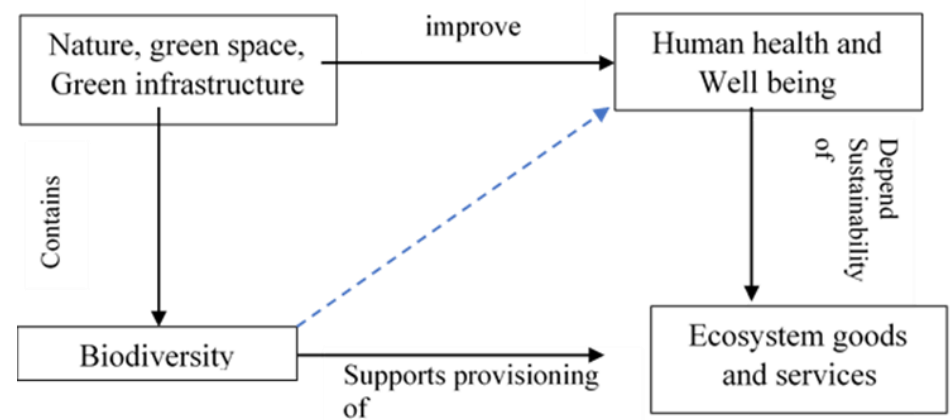

Figure 2. Linkages between nature, biodiversity, ecosystem services, and human health and well-being (Aerts et al., 2018).

tems to offer fundamental services of sustainable existence, often leading to negative health and wellbeing effects. The degradation of the ecosystem can cause loss of biodiversity and risks of infection. Figure 2 represents the biodiversity, human health and ecosystem services. A wide variety of species are dependent upon the ecosystems, including food production systems, such as primary producers and herbivores, carnivores, and decomposers. Ecosystem services include food, clean air, freshwater, medicines, religious and traditional values, climate change regulations, the regulation of pests and diseases, and the decrease of disaster risk. The conservation and appropriate use of biodiversity can be beneficial to human health by conserving ecosystem services and alternative for the future. Because human health is inextricably related to the temperature ranges in which societies have been accustomed, deviations from ideal temperatures will influence morbidity and death (Gasparini et al., 2015). One of the aspects of health hazards is temperature extremes. Heatwaves have already surpassed any other extreme weather-related occurrence in Europe in terms of cumulative death rates (European Environment Agency, 2017).

Biodiversity can have an impact on one's health and well-being by preventing or lowering illness. Among the most compelling examples of the importance of biodiversity to human health is medicinal medications obtained from natural sources. Natural products and genetic resources are found in biodiverse habitats, which are used in both traditional and modern medicine (van Wyk and Wink, 2017). For the majority of the human population, medicinal plants are the principal source of natural product medications (Romanelli et al., 2015). Ekor (2014) according to study, found that 70-80 percent of the world's population is thought to rely on traditional medicine for their primary health care. Natural products account for $75 \%$ of all antibacterial, antiviral, and antiparasitic medications licensed in the United States (Newman and Cragg, 2012). Changing impacts on biodiversity have resulted in the availability of clean water for human consumption (World Health Organization, 2019). Biodiversity is critical to the provision and regulation of water quantity and quality. Much of the world's fresh water is supplied via river networks downstream from mountains, and forests play a significant role in flow management (Zhang et al., 2017). Biodiversity is essential to the ecosystem's health because it supports 
ecosystem activities such as providing, regulating, and purifying freshwater.

\section{Biodiversity, food production, supply chain and soil nutrition}

\section{Soil nutrition and biodiversity}

Soil biodiversity's functional features are quickly evolving, partly as a result of the growing acknowledgment because of its importance in ecological processes and partly because of the benefits of excellent soils to public health and well-being. Rational soil use techniques must allow for economically and environmentally sustainable yields, which can only be achieved if soil health is maintained or restored. Cardoso et al. (2012) described soil health as the ability of soil, within ecological and land-use limitations, to work as a vital living system to sustain ecological integrity, enhance air and water quality, and maintain plant, animal, and human health. Soils and soil biodiversity, like most of the resources people rely on, are threatened by land degradation, climate change, pollution, urbanization, and overuse and exploitation (Montanarella et al., 2015). Soil biodiversity is important for biological soil water consumption, but many organisms also help with physical and chemical interactions between water and soil matrix. Soils and soil biodiversity like the majority of the resources on which people rely, are under threat from land degradation, climate change, pollution, urbanization, and overuse and exploitation. Nutrient transit across trophic levels is essential in both natural and agricultural ecosystems, and is predominantly mediated by soil fauna and microorganisms.. In a climax forest, up to $95 \%$ of nitrogen recirculates in an almost closed soil-plant-microorganisms circuit (Chen et al., 2003). The soil fauna and microbial population are important in any ecosystem because they influence soil organic matter decomposition, nutrient cycling, and soil chemical and physical properties, all of which have direct implications for soil fertility and sustainability. Soil biota, unlike most chemical and physical qualities, is very dynamic and is swiftly modified by soil usage and management, as well as any other disturbance. That is why edaphic organisms are useful markers of soil health, particularly when the indication corresponds to biological processes in the soil. Soil biodiversity is increasingly recognized as critical to the supply of ecological services for human well-being. Soil biota plays the role in:

- Formation of the soil, breakdown of organic matter, and nutrient cycling

- The control or eradication of the plant, pests and diseases;

- The synthesis of plant growth hormones;

- The supply of water can be regulated by adjusting soil structure, as well as water infiltration and storage.

- Flood and erosion control by soil structure change and water infiltration

Furthermore, soil biota affects climate by storing carbon and producing and consuming greenhouse gases (Bissett et al., 2013). Soil biodiversity is widely known for its function in regulating greenhouse gas emissions and soil carbon storage (Jackson et al., 2017). Climate, plant diversity, and soil biodiversity all interact to affect the balance of carbon in soils (Schimel et al., 2012). Soil organisms also 
help with litter breakdown and greenhouse gas emissions. Soil fauna enhances the surface area of litter by shredding leaves, which boosts microbial decomposition rates (Moore et al., 2004). In moderate and wet tropical regions, soil fauna generally increases litter decomposition rates, although this is not always the case in cold, dry regions (Frouz et al., 2015).

Recent research suggests that global climate changes impact the soil biota and modulate some ecological services, indicating that global change is one of the largest dangers to soil biodiversity (Garcia et al., 2015). In addition, rate of change of the environment, and the species sensitivity all influences the amount of global changes which affects soil biodiversity and functioning of ecosystem. The potential for a disconnect between above ground and belowground communities, changes in plant-soil feedbacks, negative effects of soil biodiversity loss on the resistance and resilience of ecosystem functioning to perturbation, and decreased ability of ecosystems to adapt to environmental change are just a few of the key concerns about global change impacts. These impacts have led to soil health chemical properties are that are linked to the ability to deliver nutrients to plants and/or to retain chemical components or chemicals that are damaging the environment and plant growth. The key chemical features employed in soil health assessment include $\mathrm{pH}$, cation exchange capacity (CEC), organic matter, and nutrient levels, especially when considering the soil capability for supporting high yield crops (Kelly et al., 2009). Soil organic carbon has an impact on critical functional activities in the soil, such as nutrient storage, particularly nitrogen storage, water holding capacity, and aggregate stability (Silva and Sá-Mendonça, 2007). Microbial activity is also influenced by soil organic carbon. As a result, especially in tropical climates, this is an important component of soil fertility that interacts with chemical, physical, and biological soil qualities and must be considered in soil health evaluation. Nitrogen is the most important nutrient for the plants, and it can be found in various of chemical formation in soil (Cantarella, 2007), resulting in highly dynamic behaviour. Nitrogen in soil has mostly been assessed as mineral nitrogen, particularly nitrate, organic nitrogen, or potentially mineralizable nitrogen, as stored in organic materials in the soil. Microbial respiration is reduced in the long run by changes in vegetation, such as deforestation which lead to depletion of surface or rhizosphere organic carbon inputs into the soil (Bissett et al., 2013).

After such a disturbance, soil with a high microbial diversity has a better chance of maintaining biological processes. Resilience is a term that refers to a biological buffering system that protects an environment against disruptions. Individual biochemical properties have a considerable degree of fluctuation in response to climate, season, geographic location, and paedogenetic factors, which is the fundamental drawback of employing them as indicators of soil quality. Changes in land use have an impact on soil carbon storage, resulting in quantitative and qualitative changes in soil organic matter, as well as physical and chemical qualities that directly affect soil microorganisms, such as humidity, porosity, and density.

In contrast to climate change precipitation is one of the most important limitations on soil biota in many ecosystems, as well as one of the most important elements influencing microbial activity, owing to its impact on soil moisture content. Reduced precipitation has a detrimental influence on fungal biomass, collembolans, and enchytraeids, according to meta-analysis, with no discernible impact on other taxa 
(Blankinship et al., 2011). Pereira et al., (2013) Reduced precipitation alters microbial community composition, implying that the ecosystem functioning may be harmed even if overall microbial biomass remains unchanged. Changes in precipitation volume, frequency, or seasonality are expected to have profound effects belowground, especially in dryland ecosystems where water is already scarce.

\section{Agriculture and biodiversity}

Biodiversity is critical for preserving natural ecosystem services that support global food, fiber, fuel, and fodder production. It's also one of the planet's most important regulators, allowing it to adapt to changing environmental conditions. Food and agricultural biodiversity (BFA) is a subset of biodiversity that aids in the production of food. It includes domesticated plants (crops), animals (livestock), aquaculture systems (fish farms), and forestry (timber), as well as other necessities such as cotton for textiles, biofuel components, and medicinal plants. BFA is just as reliant on the biodiversity as it is on food production and security. The global move to more intense agricultural and aquatic food production systems, on the other hand, is disrupting the environments where BFA thrives. As the world's population continues to grow, more land will need to be dedicated to agricultural production to satisfy the projected increase in food demand. This has the potential to increase the conversion of previously uncultivated land or to expand agricultural activities on land already exploited for food production. Agricultural biodiversity provides humans with food, raw materials for items such as cotton and wool for clothes, wood for shelter and fuel, herbs and roots for remedies, and biofuel materials. Agricultural biodiversity also provides ecosystem services such as soil and water conservation, soil fertility maintenance, biota conservation, and plant pollination, all of which are critical for food production and human survival. Stiles (2017) studied farmland habitat, also known as the agroecosystem, which is possibly the most important environment in the UK in terms of wildlife and biodiversity, as it accounts for about 75 percent of the country's land use. This environment has recently been linked to biodiversity loss and a decrease in the presence of wildlife as a result of postwar agricultural intensification.

Land use and intensity, of management are significant elements in the agro-biodiversity, ecosystems since both restrict food and wildlife availability. Management measures, like fertilizer, uses, grassland intensity, and grassland, moving frequencies have been demonstrated in a process called biotic homogenization to cause biodiversity loss. Crop production and livestock is an important driver of biodiversity loss which accounts for $50 \%$ of the total living area (excluding ice-covered land, etc.). This has caused habitat fragmentation, its condition deterioration, and its connectedness (the extent to which species or other environmental resources, such as nutrients, can move between similar habitat patches). In temperate zones, there are croplands even in many protected areas (Vijay and Armsworth, 2021). Climate change leads to a very high land, degradation rate, which leads to increased desertification and nutrient soils. The problem of land degradation is growing every day and is a huge worldwide problem. That has caused changes in soil processes that affect important soils are adversely affected properties like structure, organic content, capability for water retention, fertility, and $\mathrm{pH}$. Changes in 
soil properties are largely due to changes in the variety and organization of living creature populations in soils. The occurrence of Water and wind erosion is predicted to grow because of increased seasonal precipitation differences with increased precipitation intensity and warmer temperatures leading to more drying out. Furthermore, significant changes in the soil's organic carbon content will vary with soil type and agricultural management. It has the dependence on the balance between inputs of carbon and losses of carbon occurring. Higher crop productivity and so more carbon inputs but also greater soil respiration rates will be present in warmer conditions, in which water is not a limiting issue. This makes it difficult to anticipate the net effect on soil carbon.

\section{Impacts on agriculture-ecosystem}

The major consequences of climate change across the agricultural ecosystem

Forestry: Warmer temperatures and extended seasons will promote growth in cooler, upland places, whereas in drier summer areas circumstances, will inhibit growth, particularly in the South and East, and could lead to drought, stress and fatality, especially among young trees (Marselle and Matthews, 2016).

Horticulture: Warmer temperatures are favourable to many vegetable crops generally, although new kinds may be needed to preserve production from winter chilling kinds. Lower precipitation can lead to drought stress in tree crops.

Livestock: The quantity and quality of food will have an impact on livestock productivity. Some livestock diseases may be more common (Morison and Matthews, 2016).

Soil: Warmer temperatures and less precipitation can lead to a loss of soil carbon, especially in peatland soils. Soil structure and fertility can be affected.

Groundwater: Reduced aquifer recharge and increased agricultural demand for water may limit groundwater supply for irrigation.

Grassland: Warmer temperatures and longer growing seasons are expected to boost grassland output, while changes in seasonal timing and rainfall amount will have an impact.

Land use: Temperature and rainfall variations will alter the classification of land suitability in some locations, potentially opening up chances for the cultivation of new crops, such as bioenergy crops.

River flooding: River flooding is predicted to become more frequent in the future, damaging crop and pasture productivity on neighbouring land.

Uplands: Warmer and drier circumstances will enhance production in colder, wetter highland locations, however more intense rainfall in some regions may result in increased soil erosion. The variety and quality of ecosystem services provided by upland areas may be influenced in both good and negative ways (Brown et al., 2010).

Arable land: Warmer temperatures suggest that crop growing seasons will begin earlier, that crops may have lesser yields due to maturation occurring sooner. Increasing the frequency of summer droughts will reduce yields in some locations, but higher winter rainfall may result in more waterlogging, increased compaction, and decreased land trafficability (Morison and Matthews, 2016).

Efforts for restoring agricultural biodiversity 
Efforts are being undertaken for germplasm build-up, management, and evaluation of targeted underused crop species through 21 National Bureau of Plant Genetic Resources (NBPGR) centers located in diverse agro-climatic zones across India. The program's goals are mentioned below.

- To discover new plant sources for food and feed as well as industrial applications

- To acquire a large collection of germplasm as well as to characterize, conserve, and improve them.

- These crops are suitable for a variety of farming scenarios.

- To develop a suitable set of agronomic procedures for their commercial cultivation.

- To distribute information about possible species to increase their popularity.

- The Global Plan of Action for Plant Genetic Resources Conservation includes 20 actions. The majority of activities have received adequate attention in India. Over time, priorities have been refined (Richa et al., 2015).

\section{Conservation measures}

Biodiversity is vital for ecosystem function and services on which humans rely and is intimately linked to the economic, social, and environmental domains of sustainability, climate change has had an impact on biodiversity loss. It will be necessary to implement specific conservation measures in order to avoid biodiversity loss. Biodiversity conservation is concerned with the preservation of life on Earth in all of its forms, as well as the functioning and health of natural ecosystems. This includes protection, maintenance, long-term usage, rehabilitation, and promotion of biological diversity components. Where conservation refers to the responsible use of resources, which includes both protection and exploitation, and preservation refers to the act of preserving something without altering or modifying it. Another complex component of biodiversity conservation is sustainable development. This refers to the development that meets the current generation's demands without jeopardizing future generations' ability to meet their own. It simply means intergenerational equity also sustainable development ensures biodiversity conservation when there is a balance between the environment, development, and society. This is only possible if policies, conventions, and environmental institutions are properly enforced and implemented (Rawat and Agrawal, 2015).

\section{Identifying the risks of changing land use patterns}

Remote sensing, which is becoming increasingly precise and widespread, allows for exact evaluations of the major driver of extinction: habitat loss. Enhanced remote sensing is particularly important since tropical moist forests are home to roughly two-thirds of all terrestrial species, and a subset of them biodiversity hotspots - are home to the vast majority of vulnerable species. RS is particularly valuable for detecting change due to the systematic coverage and lengthy-time series offered by satellite data. RS data and derivatives are critical inputs to models that forecast future states and patterns, allowing for early detection of change and quick intervention. Rates of change, rather than absolute changes, may be more important, making the frequency of repeats in a time series, as well as data continuity, significant. 
The use of remote sensing to construct maps of terrestrial ecosystems is frequent. These maps are often based on a map that delineates specific vegetation types or land uses. The problem is that remote sensing must be combined with fast increasing data on species distributions in order to identify future fronts of species extinction, and adaption of these conservation measures helps to minimize climate change and global warming impacts. Conservation applications necessitate a connection that is fast enough for law policies, conservation groups, and others to respond. RS is critical for identifying and monitoring dynamic trends that influence ecosystems, species, and ecosystem services, with genome effects being a new area of study. Global area maps for terrestrial vertebrates are available, based on informal species distribution records and expert analysis (Ocampo and Pimm, 2014). Linking species habitat preferences with the qualities that satellites measure is required for remotely assessing land-use changes for species that live entirely or partially in different habitats. Species ranges are determined from data on species localities. Locality data might be linked directly to remote sensing, which would be a computationally difficult process but would eliminate intermediate steps. Remote sensing also offers information about the area's freshwater system, including flood mapping based on satellite measurements of the water body, retention time, and hydro-period. The estimations of chlorophyll level in water surface, sediment, and coloured dissolved organic matter concentrations, as well as estimates the water depth and clarity using optical RS, can be used to evaluate the trophic status of the water column. More can be done to increase the greater biodiversity conservation community's availability and use of RS. The use of RS is essential for monitoring land, marine, and aquatic life. Since more and different types of sensors are available, and as cooperation with the greater community improves, RS may play an increasingly vital role, providing global, periodic data that can improve our understanding of change and how society responds to it. (Walters and Scholes, 2017).

\section{Protecting the wildlife sites}

The distribution of biodiversity over the land and sea is significantly non-uniform. Because of geology, climate, topography, and human activity, some areas are more abundant and diverse in terms of species, abundance and diversity than others. Many species rely on the conservation and management of such ecosystems. Priorities are to be accorded to wildlife refuges as areas of ecological biodiversity conservation and protection, with no human intrusion. The nature wildlife sanctuary has been proven to be a location of the highest moral responsibility, where people willingly limit their rights and freedoms for the protection of the rights and freedoms of wildlife and other living creatures, with the best of intentions. National parks are nature preservation, ecological, educational, and scientific institutions, with natural complexes and artifacts of unique ecological, historical, and aesthetic value inside their territories (water areas). They're made to be used in environmental, educational, scientific, and cultural settings, as well as for controlled tourism. This is a critical component of conservation strategy, delivered through an evidence-based framework that identifies the most important regions. Offers legal protection, influences activity within their bounds, and seeks restoration to restore the damage that happens within them. These locations are critical components of the strategy to ensure that biodiversity can adapt to environmental changes, notably climate change (Gorbunov et al., 2019). 


\section{Priority species and habitats}

Climate change is another additional concern to species, and its current and future effects are likely to worsen existing stressors (Hof et al., 2011). Due to the limitation, it is critical to assess which species are most vulnerable to climate change, whether current management locations are still suitable for target species, where future conservation areas must be targeted, and whether species will seek help migrating between current and future management areas. Priority habitats and species cannot be managed in solitude. The Ecosystem approach emphasizes the preservation of ecosystem structure and function to preserve ecosystem services. Ecosystems must be considered as a whole, and how many of the component's functions are dependent on one another, especially as these interactions respond to climatic and other environmental changes, following this thinking and the Millennium Ecosystem Assessment method. As a result, action will be taken to reduce the fragmentation of critical habitats and constraints on biodiversity in the larger environment in which species travel. Some of the new goals, such as increasing the patch sizes of grassy habitats and building landscape-scale complexes for wetlands, reflect these broader, landscape-scale initiatives Morison (Ruddock et al., 2007).

\section{Conclusion}

Biodiversity is a cornerstone of basic life not an optional addition in human matters. The conservation of biodiversity adapted to changing climate conditions is essential not just for species and habitats to adapt to change, but also for climate change mitigation. Halting biodiversity loss is a huge challenge, particularly in light of climate change, which will exacerbate many of the adverse drivers. The most important environmental worry of the decade is climate change. Carbon reduction requires a great deal of awareness and greenhouse gas emissions from energy, and its impact on water resources, human health, species, and agricultural practices. The influence of climate change on biodiversity and various components of nature are affected. Since, biodiversity refers to the diversity of all kinds of life, from genes to ecosystems. Changes in the fundamentals of biodiversity will have an impact on changes in biodiversity and its natural habitat on a broad scale. Furthermore, climate change has had a substantial impact on the flora, fauna, and species habitat, as well as on human health. These effects have had a significant impact on the natural environment of plants, animals, soil nutrients, and all other components. By storing carbon and creating and consuming greenhouse gases, soil biota has an impact on climate. Chemical qualities of soil quality are related to the ability of the soil to provide micronutrients and/or to retain active compounds or chemicals that are harmful to the environment and plant growth as a result of the impacts. Soil nutrient imbalances have harmed agricultural and crop output to meet global food demand. Certain technology and socio-economic measures to maintain biodiversity must be adopted to reduce the impact of climate change on biodiversity loss and their side effects on the environment. Changes in land patterns in a place over time might aid in monitoring changes in forest cover or vegetation in that area. As a result, conservation measures could be implemented to protect the area's forest species and animal species. Remote sensing technology is being 
used to create maps of natural ecosystems, which are typically based on a map that distinguishes different vegetation cover or land uses. The method of combining remote sensing with rapidly increasing data on species distributions in order to predict future fronts of species extinction and adapting conservation techniques to help mitigate the effects of climate change. Soil nutrients and endangered species can be protected in the area. Climate change has an impact on a variety of soil processes, notably those related to soil fertility. By monitoring the land change cover in the area, degradation of soil could be detected and the productivity of the soil can be maintained by taking measures to meet the global demand for crops and food. These measures help to mitigate climate change and reduce global warming.

\section{Acknowledgment}

The author is thankful to Dr. Rohitashw Kumar, Professor, COAE\&T, Sher-e-Kashmir University of Agricultural Sciences and Technology, and Dr. Rishi Richa, Assistant Professor, COAE\&T, Sher-e-Kashmir University of Agricultural Sciences and Technology for their valuable assistant and suggestion in the formulation of the chapter. The author would like to express gratitude towards COAE\&T, Sher-e-Kashmir University of Agricultural Sciences and Technology, Srinagar for providing the opportunity to grow as a researcher.

\section{References}

Adelodun, B., Kareem, K.Y., Kumar, P., Kumar, V., Choi, K.S., Yadav, K.K., and Khan, N.A. (2021a). Understanding the impacts of the COVID-19 pandemic on sustainable agri-food system and agroecosystem decarbonization nexus: A review. Journal of Cleaner Production, 318: 128451.

Adelodun, B., Ajibade, F.O., Tiamiyu, A.O., Nwogwu, N.A., Ibrahim, R.G., Kumar, P., and Choi, K.S. (2021b). Monitoring the presence and persistence of SARS-CoV-2 in water-food-environmental compartments: State of the knowledge and research needs. Environmental Research, 111373: 1-17.

Aerts, R., Honnay, O. and Van Nieuwenhuyse, A. (2018). Biodiversity and human health: mechanisms and evidence of the positive health effects of diversity in nature and green spaces. British Medical Bulletin, 127(1): 5-22.

Balasubramanian, A. (2008). Ecosystem and its components. Centre for Advanced Studies in Earth Science: University of Mysore, India, pp. 28.

Bellard, C., Bertelsmeier, C., Leadley, P., Thuiller, W. and Courchamp, F. (2012). Impacts of climate change on the future of biodiversity. Ecology Letters, 15(4): 365-377.

Bissett A, Brown M.V, Siciliano S.D and Thrall P.H. (2013). Microbial community responses to anthropogenically induced environmental change: towards a systems approach. Ecology Letters, 16: 128-39.

Blankinship J.C, Niklaus P.A and Hungate B.A. (2011). A meta-analysis of responses of soil biota to global change. Oecologia 165: 553-65.

Brown, S., Boorman, P. and Murphy, J. (2010). Interpretation and use of future snow projections from the 11-member Met Office Regional Climate Model Ensemble. Met Office Hadley Centre, Exeter, November 2010.

Burnham, M. and Ma, Z. (2015). Linking smallholder farmer climate change adaptation decisions to development. Climate and Development, 8: 1-10.

Cantarella, H. (2007). Nitrogênio = Nitrogen. In: Novais, R.F.; Alvarez, V.; Barros, N.F.; Fontes, R.L.F.; Cantarutti, R.B.; Neves, 
J.C.L., eds. Fertilidade do solo = Soil fertility. Sociedade Brasileira de Ciência do Solo, Viçosa, MG, Brazil. (in Portuguese), pp. 375-470. .

Cardoso, E.J.B.N., Vasconcellos, R.L.F., Bini, D., Miyauchi, M.Y.H., Santos, C.A.D., Alves, P.R.L., Paula, A.M.D., Nakatani, A.S., Pereira, J.D.M. and Nogueira, M.A. (2013). Soil health: looking for suitable indicators. What should be considered to assess the effects of use and management on soil health?. Scientia Agricola, 70(4): 274-289.

Ceballos, G., Ehrlich, P.R., Barnosky, A.D., García, A., Pringle, R.M. and Palmer, T.M. (2015). Accelerated modern human-induced species losses: Entering the sixth mass extinction. Science Advances, 1(5): 1400253.

Chen, G., Zhu, H. and Zhang, Y. (2003). Soil activities and carbon and nitrogen fixation. Research in Microbiology 154: $393-398$.

Davey, C.M., Devictor, V., Jonzén, N., Lindström, Å. and Smith, H.G. (2013). Impact of climate change on communities: revealing species' contribution. Journal of Animal Ecology, 82(3): 551-561.

Ekor, M. (2014). The growing use of herbal medicines: issues relating to adverse reactions and challenges in monitoring safety. Frontiers in Pharmacology, 4: 177.

European Environment Agency (2017). Climate Change, impacts and vulnerability in Europe: An indicator-based report. Copenhagen. pp. 25.

Frouz, J., Roubíčková, A., Heděnec, P. and Tajovsky, K. (2015). Do soil fauna really hasten litter decomposition? A metaanalysis of enclosure studies. European Journal of Soil Biology, 68: 18-24.

García-Palacios, P., Vandegehuchte, M.L., Shaw, E.A., Dam, M., Post, K.H., Ramirez, K.S., Sylvain, Z.A., de Tomasel, C.M. and Wall, D.H. (2015). Are there links between responses of soil microbes and ecosystem functioning to elevated $\mathrm{CO}_{2}, \mathrm{~N}$ deposition and warming? A global perspective. Global Change Biology, 21(4): 1590-1600.

Gasparrini, A., Guo, Y., Hashizume, M., Lavigne, E., Zanobetti, A., Schwartz, J., Tobias, A., Tong, S., Rocklöv, J., Forsberg, B. and Leone, M. (2015). Mortality risk attributable to high and low ambient temperature: a multicountry observational study. The Lancet, 386(9991): 369-375.

Gorbunov, M.A., Fadeeva, A.V., Shirshikov, V.B., Matveev, P.A., Popova, O.V., Mitrofanova, M.Y., Bakaeva, J.Y. and Mashkin, N.A. (2019). Nature protection potential of wildlife sanctuary: Protection and Preservation of its Ecological Biodiversity. Ekoloji, 28(107): 5033-5037.

He, J., Yan, C., Holyoak, M., Wan, X., Ren, G., Hou, Y., Xie, Y. and Zhang, Z. (2018). Quantifying the effects of climate and anthropogenic change on regional species loss in China. PloS One, 13(7): 0199735.

Hillebrand, H., Blasius, B., Borer, E.T., Chase, J.M., Downing, J.A., Eriksson, B.K., Filstrup, C.T., Harpole, W.S., Hodapp, D., Larsen, S. and Lewandowska, A.M. (2018). Biodiversity change is uncoupled from species richness trends: Consequences for conservation and monitoring. Journal of Applied Ecology, 55(1): 169-184.

Hof, C., Araújo, M.B., Jetz, W. and Rahbek, C. (2011). Additive threats from pathogens, climate and land-use change for global amphibian diversity. Nature, 480(7378): 516-519.

IPBES. (2019). Global Assessment Report on Biodiversity and Ecosystem Services of the Intergovernmental Science-Policy Platform on Biodiversity and Ecosystem Services.

IPBES. (2020). Workshop Report on Biodiversity and Pandemics of the Intergovernmental Platform on Biodiversity and Ecosystem Services. Bonn, Germany.

IPCC (2007). An assessment of Intergovernmental Panel on climate change. Climate change synthesis report, Cambridge University Press, Cambridge, U.K. pp. 73.

IPCC (2013). Climate Change, The Physical Science Basis. Cambridge University Press, U.K.

Jackson, R.B., Lajtha, K., Crow, S.E., Hugelius, G., Kramer, M.G. and Piñeiro, G. (2017). The ecology of soil carbon: pools, vulnerabilities, and biotic and abiotic controls. Annual Review of Ecology, Evolution, and Systematics, 48: 419-445.

Jenkins, C.N., Pimm, S.L. and Joppa, L.N. (2013). Global patterns of terrestrial vertebrate diversity and conservation. Proceedings of the National Academy of Sciences, 110(28): E2602-E2610.

Johnston, A., Ausden, M., Dodd, A.M., Bradbury, R.B., Chamberlain, D.E., Jiguet, F., Thomas, C.D., Cook, A.S., Newson, S.E., Ockendon, N. and Rehfisch, M.M. (2013). Observed and predicted effects of climate change on species abundance in protected areas. Nature Climate Change, 3(12): 1055-1061.

Kelly, B., Allan, C. and Wilson, B.P. (2009). Soil indicators and their use by farmers in the Billabong Catchment, southern New 
South Wales. Australian Journal of Soil Research, 47: 234-242.

Kempton, R.A. (2002). Encyclopedia of Environmetrics. 4 Vol, Chichester: John Wiley \& Sons, Ltd.

Khaine, I., Woo, S.Y., Kang, H., Kwak, M., Je, S.M., You, H., Lee, T., Jang, J., Lee, H.K., Lee, E. and Yang, L. (2017). Species diversity, stand structure, and species distribution across a precipitation gradient in tropical forests in Myanmar. Forests, 8(8): 282.

Kiers, E.T., Palmer, T.M., Ives, A.R., Bruno, J.F. and Bronstein, J.L. (2010). Mutualisms in a changing world: an evolutionary perspective. Ecological Letters, 13: 1459-1474.

Lambin, E. F. and P. Meyfroidt. (2011).Global Land Use Change, Economic Globalization, and the Looming Land Scarcity. Proceedings of the National Academy of Sciences, 108: 3465-3472.

Lindner, M., Maroschek, M., Netherer, S., Kremer, A., Barbati, A., Garcia-Gonzalo, J., Seidl, R., Delzon, S., Corona, P., Kolstrom, M., Lexer, M.J., Marchetti M (2010) Climate change impacts, adaptive capacity, and vulnerability of European forest ecosystems. Forest Ecology Management, 259(4): 698-709

Marselle, M.R., Stadler, J., Korn, H., Irvine, K.N. and Bonn, A. (2019). Biodiversity and health in the face of climate change. Springer Nature, pp.481

McCarthy, M.A., Thompson, C.J., Moore, A.L. and Possingham, H.P. (2011). Designing nature reserves in the face of uncertainty. Ecology Letters, 14(5): 470-475.

Montanarella, L., Pennock, D.J., McKenzie, N.J., Badraoui, M., Chude, V., Baptista, I., Mamo, T., Yemefack, M., Singh Aulakh, M., Yagi, K. and Young Hong, S. (2015). World's soils are under threat. SOIL Discussions, 2(2): 1263-1272.

Moore, J.C., Berlow, E.L., Coleman, D.C., de Ruiter, P.C., Dong, Q., Hastings, A., Johnson, N.C., McCann, K.S., Melville, K., Morin, P.J. and Nadelhoffer, K. (2004). Detritus, trophic dynamics and biodiversity. Ecology Letters, 7(7): 584-600.

Morison, J.I.L. and Matthews, R.B. (2016). Agriculture and Forestry Climate Change Impacts Summary Report, Living with Environmental Change.

Mukhopadhyay, T. and Bhattacharjee, S. (2016). Genetic Diversity: Its Importance and Measurements. Conserving Biological Diversity: A Multiscaled Approach, pp. 251-295.

Newman, D.J., Cragg, G.M. (2012). Natural products as sources of new drugs over the 30 years from 1981 to 2010 . Journal of Natural Production, 75: 311-335.

Ocampo-Penuela, N. and Pimm, S.L. (2014) Setting practical conservation priorities for birds in the Western Andes of Colombia. Conservation Biology, 28: 1260-1270.

Pawson, S.M., Brin, A., Brockerhoff, E.G., Lamb, D., Payn, T.W., Paquette, A. and Parrotta, J.A. (2013). Plantation forests, climate change and biodiversity. Biodiversity and Conservation, 22(5): 1203-1227.

Pereira, E.I.P., Chung, H., Scow, K.M. and Six, J. (2013). Microbial communities and soil structure are affected by reduced precipitation, but not by elevated carbon dioxide. Soil Science Society of America Journal, 77: 482-88.

Pimm, S.L., Jenkins, C.N., Abell, R., Brooks, T.M., Gittleman, J.L., Joppa, L.N. and Sexton, J.O. (2014). The biodiversity of species and their rates of extinction, distribution, and protection. Science, 344: 987.

Rao, V.R. and Hodgkin, T. (2002). Genetic diversity and conservation and utilization of plant genetic resources. Plant Cell, Tissue and Organ Culture, 68(1): 1-19.

Rawat, U.S. and Agarwal, N.K. (2015). Biodiversity: concept, threats and conservation. Environment Conservation Journal, 16(3): 19-28.

Reilly, M.J. and Spies, T.A. (2015). Regional variation in stand structure and development in forests of Oregon, Washington, and inland Northern California. Ecosphere, 6(10): 1-27.

Richa, R., Omre, P.K. and Shukla, R. (2015). Traditional seed processing and storage: A need to retain minimum crop diversity in India. South Asian Journal of Food Technology and Environment, 1(2): 160-166.

Romanelli, C., Cooper, D., Campbell-Lendrum, D., Maiero, M., Karesh, W.B., Hunter, D. and Golden, C.D. (2015). Connecting global priorities: biodiversity and human health: a state of knowledge review. World Health Organisation/Secretariat of the UN Convention on Biological Diversity.

Ruddock, J., Russell, M., Davidson, J. and Foster, A. (2007). Conserving biodiversity: the UK approach. Conserving biodiversity: the UK approach. 
Schimel, J. and Schaeffer, S.M. (2012). Microbial control over carbon cycling in soil. Frontiers in Microbiology, 3: 348.

Sevegnani, L., Uhlmann, A., de Gasper, A.L., Meyer, L. and Vibrans, A.C. (2016). Climate affects the structure of mixed rain forest in southern sector of Atlantic domain in Brazil. Acta Oecologica, 77: 109-117.

Shen, Z. and Ma, K. (2014). Effects of climate change on biodiversity. Chinese Science Bulletin, 59: 4637-4638.

Silva, I.R. and Sá Mendonça, E. (2007). Materia organica do solo = Soil organic matter. In: Novais, R.F.; Alvarez, V.H.; Barros, N.F.; Fontes, R.L.F.; Cantarutti, R.B.; Neves, J.C., eds. Fertilidade do solo = Soil fertility. Sociedade Brasileira de Ciencia do Solo, Viçosa, MG, Brazil. pp. 275-374.

Sintayehu, D.W. (2018). Impact of climate change on biodiversity and associated key ecosystem services in Africa: a systematic review. Ecosystem Health and Sustainability, 4(9): 225-239.

Staudinger, M.D., Grimm, N.B., Staudt, A., Carter, S.L. and Chapin, F.S. (2012). Impacts of climate change on biodiversity, ecosystems, and ecosystem services. United States Global Change Research Program, Washington, DC, pp. 296.

Stiles, W. (2017). The importance of biodiversity and wildlife on farmland. Farming Connect, 1-10, http:// hdl.handle.net/2160/44987

Thomas, K.A. and Warner, B.P. (2019). Weaponizing vulnerability to climate change. Global Environmental Change, $57: 101928$.

Thuiller W. (2007). Climate change and the ecologist. Nature, (2): 550-552.

United Nations Framework Convention on Climate Change, (2007). Impacts, vulnerabilities and adaptation in developing countries.

Van Wyk, B.-E. and Wink, M. (2017). Medicinal Plants of the World. CABI.

Vijay, V. and Armsworth, P.R. (2021). Pervasive cropland in protected areas highlight trade-offs between conservation and food security. Proceedings of the National Academy of Sciences, 118(4): 1-10.

Walters, M. and Scholes, R.J. (2017). The GEO handbook on biodiversity observation networks. Springer Nature, pp. 326

Walther, G. R. (2010). Community and ecosystem responses to recent climate change. Philosophical Transactions of the Royal Society B-Biological Sciences, 365: 2019-2024.

Ward, N.L. and Masters, G.J. (2007). Linking climate change and species invasion: an illustration using insect herbivores. Global Change Biology, 13(8): 1605-1615.

Warren, R., VanDerWal, J., Price, J., Welbergen, J.A., Atkinson, I., Ramirez-Villegas, J., Osborn, T.J., Jarvis, A., Shoo, L.P., Williams, S.E. and Lowe, J. (2013). Quantifying the benefit of early climate change mitigation in avoiding biodiversity loss. Nature Climate Change, 3(7): 678-682.

World Health Organization. (2015). Connecting global priorities: biodiversity and human health. World Health Organization and Secretariat of the Convention on Biological Diversity.

Zhang, M., Liu, N., Harper, R., Li, Q., Liu, K., Wei, X., Ning, D., Hou, Y. and Liu, S. (2017). A global review on hydrological responses to forest change across multiple spatial scales: Importance of scale, climate, forest type and hydrological regime. Journal of Hydrology, 546: 44-59.

Zhong, L., and J. Wang. (2017). Evaluation on Effect of Land Consolidation on Habitat Quality Based on Invest Model. Transations of the Chinese Society of Agricultural Engineering, 33: 250-255.

Cite this chapter as: Mishra, A., Kumar, R. and Richa, R. (2021). Biodiversity conservation to mitigate the impact of climate change on agro-ecosystems. In: Biological Diversity: Current Status and Conservation Policies, Volume 1, Eds. Kumar., V., Kumar, S., Kamboj, N., Payum, T., Kumar, P. and Kumari, S. pp. 89-107, https://doi.org/10.26832/aesa2021-bdcp-06 